\title{
Mortality from Acute Myocardial Infarction and Other Ischemic Heart Diseases in the State of São Paulo from 1980 to 1996
}

\author{
Luiz F. Marcopito, Mírian M. Shirassu
}

São Paulo, SP - Brazil

Reports have been published regarding the decline in mortality from ischemic heart diseases (ICD-10 ${ }^{\text {th }}: 410-414$; ICD-10 ${ }^{\text {th: }}$ 129-125) in the municipality of São Paulo from 1950 to $1981^{1}$, in the State of São Paulo from 1970 to $1989^{2}$ and in a few other Brazilian capital cities from 1979 to $1989^{3}$, but no specific information is available regarding mortality from acute myocardial infarction (ICD-10 410 ; ICD-10 121 ) in the State of São Paulo, or of its participation in total mortality from ischemic heart diseases. The aim of this article is to show the evolution of mortality rates from acute myocardial infarction and the remaining ischemic heart diseases in the State of São Paulo from 1980 to 1996.

\section{Methods}

The data on specific mortality due to acute myocardial infarction and to the remaining ischemic heart diseases by usual residence of the deceased were obtained from the Datasus (provided by the System of Information of Mortality of the Health Ministry). The resident population information in census data years was obtained from the Instituto Brasileiro de Geografia e Estatística and the estimates for the years in between censuses, was obtained from the SEADE Foundation.

The mortality rates were adjusted by age using the direct method and as a reference the age structure of the total population (both sexes) of the State of São Paulo in 1980.

The trend in rates by sex during the period under study was calculated by simple linear regression, and the proportion of the total variability is explained by the linear model expressed as $r^{2}$ (the maximum possible is 1.00). In the straight-line equation $(y=a+b x)$, which will be shown, " $\mathrm{x}$ " was given the minimum value of 0 in 1980 and the maximum of 16 in 1996. The value (b), which multiplies " $x$ " in each equation, is the coefficient of inclination of the straight line. The greater the " $b$ " module, the more inclined is the line. Negative "b" values indicate a downward trend (decline).

Escola Paulista de Medicina - UNIFESP

Correspondência: Luiz Francisco Marcopito - Rua Pedro de Toledo, 675 - 04039-032 - São Paulo, SP - Brazil
The probability (p) of " $b$ " being statistically equal to zero (or of not having changes in the rates during the period) is supplied.

The percentage of annual variation was calculated from the ratio b/a.

\section{Results}

Table I shows mortality rates from acute myocardial infarction and the remaining ischemic heart diseases, by sex adjusted by age. It can be seen that an important reduction occurred during the 17 years under study, better observed in figure 1, where these rates appear individually as symbols. The lines drawn show the trend toward decline, and its intensity can be evaluated by the beta values in the equations presented in table II.

The equation of line 1, for example $(y=67.204-0.8100 x)$, indicates that from $1980(\mathrm{x}=0)$, for each unit of change in $\mathrm{x}$ (from 1 to 16 ) the mortality rate from acute myocardial infarction in men (y) declined 0.8100 of a unit on average (from $67.204)$. In percentages, this annual reduction was $1.2 \%$ $(0.8100 / 67.204 \times 100)$. The same principle applies to the remaining lines presented in table II.

It is interesting to observe in figure 1 that the rates show cyclical variations, of more and less above and below the lines, justifying the need for a general overview of the trend during the period.

To judge by the values of $r^{2}$, the linear model adjusted itself very well to the trend in mortality rates represented by 1,3 and $4\left(\mathrm{r}^{2}\right.$ in 0.86 to 0.97$)$ and a little less is represented by line $2\left(r^{2}\right.$ of 0.55$)$.

In the four series, changes (decline) occurred in the rates during the period under study $(\mathrm{p}<0.001)$, and the differential of reduction in the rates caused the percentage contribution of mortality by acute myocardial infarction to mortality from all the ischemic heart diseases, in women, to come close to that in men during the period under study (fig. 2).

\section{Discussion}

The mortality rates (age adjusted) from ischemic heart 


\begin{tabular}{|c|c|c|c|c|c|c|c|c|c|c|}
\hline \multirow[b]{2}{*}{ Year } & \multirow[b]{2}{*}{$X$} & \multicolumn{3}{|c|}{ AMI } & \multicolumn{3}{|c|}{ Remaining IHD } & \multicolumn{3}{|c|}{ Total IHD } \\
\hline & & Male & Female & M:F & Male & Female & M:F & Male & Female & $\mathrm{M}: \mathrm{F}$ \\
\hline 1980 & 0 & 68.8 & 32.2 & 2.1 & 27.1 & 24.7 & 1.1 & 95.9 & 56.9 & 1.7 \\
\hline 1981 & 1 & 66.6 & 31.8 & 2.1 & 26.1 & 23.5 & 1.1 & 92.7 & 55.3 & 1.7 \\
\hline 1982 & 2 & 63.2 & 29.7 & 2.1 & 25.3 & 22.3 & 1.1 & 88.5 & 52.0 & 1.7 \\
\hline 1983 & 3 & 64.7 & 30.2 & 2.1 & 27.0 & 23.8 & 1.1 & 91.7 & 54.0 & 1.7 \\
\hline 1984 & 4 & 63.4 & 29.4 & 2.2 & 26.2 & 22.3 & 1.2 & 89.6 & 51.7 & 1.7 \\
\hline 1985 & 5 & 62.2 & 29.6 & 2.1 & 24.8 & 21.1 & 1.2 & 87.0 & 50.7 & 1.7 \\
\hline 1986 & 6 & 61.2 & 29.7 & 2.1 & 22.9 & 19.6 & 1.2 & 84.1 & 49.3 & 1.7 \\
\hline 1987 & 7 & 61.4 & 30.8 & 2.0 & 22.1 & 18.6 & 1.2 & 83.5 & 49.4 & 1.7 \\
\hline 1988 & 8 & 64.5 & 31.3 & 2.1 & 22.0 & 17.5 & 1.3 & 86.5 & 48.8 & 1.8 \\
\hline 1989 & 9 & 62.1 & 30.5 & 2.0 & 20.5 & 16.5 & 1.2 & 82.6 & 47.0 & 1.8 \\
\hline 1990 & 10 & 60.6 & 29.5 & 2.1 & 20.5 & 16.8 & 1.2 & 82.6 & 47.0 & 1.8 \\
\hline 1991 & 11 & 57.1 & 29.2 & 2.0 & 18.3 & 14.4 & 1.3 & 75.4 & 43.6 & 1.7 \\
\hline 1992 & 12 & 56.2 & 27.7 & 2.0 & 17.5 & 13.5 & 1.3 & 73.7 & 41.2 & 1.8 \\
\hline 1993 & 13 & 55.1 & 27.5 & 2.0 & 18.1 & 13.4 & 1.4 & 73.2 & 40.9 & 1.8 \\
\hline 1994 & 14 & 54.0 & 27.0 & 2.0 & 17.5 & 12.6 & 1.4 & 71.5 & 39.6 & 1.8 \\
\hline 1995 & 15 & 55.7 & 29.4 & 1.9 & 17.3 & 13.3 & 1.3 & 73.0 & 42.7 & 1.7 \\
\hline 1996 & 16 & 55.5 & 28.2 & 2.0 & 17.3 & 12.1 & 1.4 & 72.8 & 40.3 & 1.8 \\
\hline
\end{tabular}

\begin{tabular}{|c|c|c|c|c|}
\hline \multicolumn{5}{|c|}{$\begin{array}{l}\text { Table II - Models of simple linear regression for mortality rates } \\
(100,000) \text { adjusted by age, sex, acute myocardial infarction (AMI), } \\
\text { and the remaining ischemic heart disease (IHD), State of São } \\
\text { Paulo, } 1980 \text { - 1996. " } \mathrm{r} \text { "' represents the adjustment of the model } \\
\text { (the maximum possible is 1.00). "P" is the probability of no } \\
\text { changes having occurred in time, and "\% \%annual" is the mean } \\
\text { percentage variation of each year. }\end{array}$} \\
\hline Mortality rate (y) & equation line & $r^{2}$ & $\mathrm{p}$ & $\%$ annual \\
\hline AMI, male & $y=67.204-0.8100 x$ & 0.86 & $<0.001$ & -1.2 \\
\hline AMI, female & $y=31.339-0.2137 x$ & 0.55 & $=0.001$ & -0.7 \\
\hline $\begin{array}{l}\text { Remaining of } \\
\text { IHD, male }\end{array}$ & $y=27.520-0.7157 x$ & 0.94 & $<0.001$ & -2.6 \\
\hline $\begin{array}{l}\text { Remaining of } \\
\text { IHD, female }\end{array}$ & $y=24.773-0.8466 x$ & 0.97 & $<0.001$ & -3.4 \\
\hline
\end{tabular}

diseases showed a clear decline in the State of São Paulo from 1980 to 1996. The decline was more pronounced in the group "remaining of ischemic heart diseases", in which the male: female ratio showed a trend toward an increase due to a more accentuated fall in women.

In the acute myocardial infarction group, which represents the greater part of mortality from ischemic heart diseases, the reduction was much more remarkable in men than in women, and the male:female ratio, which was 2.2 in 1984, declined to 2.0 during the final years of observation.

As a result of these modifications, the percentage contribution of acute myocardial infarction to mortality from all ischemic heart diseases increased in the period under study in both sexes, but was more pronounced in women. In more recent years, about $76 \%$ of mortality from ischemic heart diseases in men was due to acute myocardial infarction (versus about $71 \%$ in the initial years of this study) and, in women, these numbers were $57 \%$ and $70 \%$, respectively.

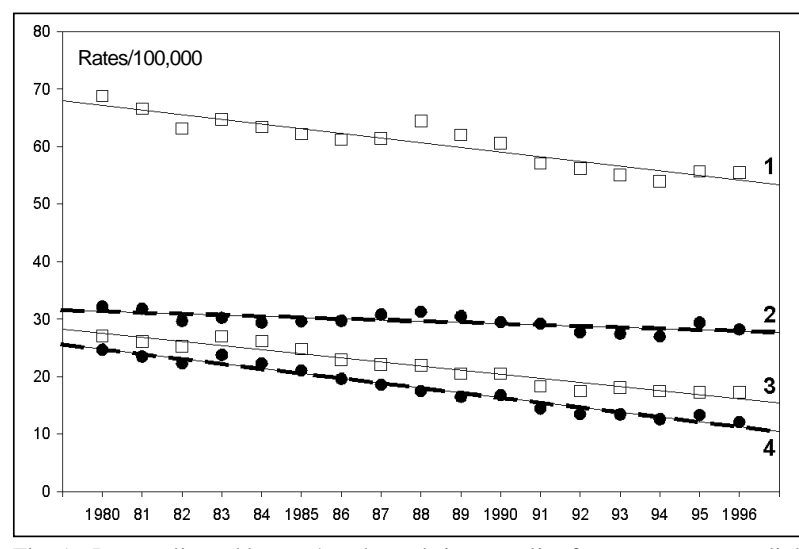

Fig. 1 - Rates adjusted by age* and trends in mortality from acute myocardial infarction (AMI) and remaining ischemic heart diseases (IHD), by sex, State of São Paulo, 1980 - 1996. 1) AMI, men, 2) AMI, women; 3) Remaining of IHD, men, and 4) Remaining of IHD, women.

* Refernce population: the total of State of São Paulo, 1980.

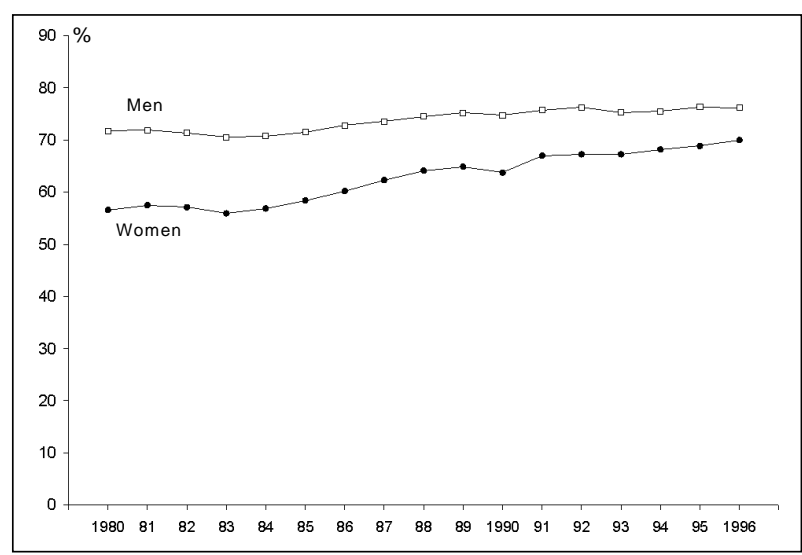

Fig. 2 - Percentage contribution of mortality rate (age adjusted*) from acute myocardial infarction to the mortality rate (age adjusted*) from all ischemic heart diseases, by sex, State of São Paulo, 1980-1996.

*Reference population: the total of the State of São Paulo, 1980 
As pointed out in the introduction, studies of population trends in mortality have focused on ischemic heart diseases as a whole, or a larger group within the circulatory diseases, in Brazil ${ }^{1-3}$ as well as internationally ${ }^{4-6}$. As far as the total of ischemic heart diseases is concerned, the trends observed in the State of São Paulo are similar to those in the United States of America from 1980 to 1988 and from 1990 to $1994^{6}$.

The comparison of these results with those in the other units of the Federation will depend on the percentage of mortality by symptoms, signs, and misdiagnosed afflictions that, in the State of São Paulo, remained around 6\% in the period under study and that, in Brazil as a whole, reached $15 \%$ of the registered mortality in 1996 .

We conclude that in the State of São Paulo, from 1980 to 1996 , occurred a decline in mortality rates from acute myocardial infarction and the remaining ischemic heart diseases, in both sexes. Acute myocardial infarction was the main cause of death from all types of ischemic heart disease and occurred primarily in men.

\section{References}

1. de Lolio CA, Laurenti R. Mortalidade por doença isquêmica do coração no município de São Paulo. Evolução de 1950 a 1981 e mudanças recentes na tendência. Arq Bras Cardiol 1986; 46: 153-6.

2. Lotufo PA, de Lolio CA. Tendência da mortalidade por doença isquêmica do coração no Estado de São Paulo: 1970 a 1989. Arq Bras Cardiol 1993; 61: 149-53.

3. de Lolio CA, Lotufo PA, Lira AC, Zanetta DM, Massad E. Tendência da mortalidade por doença isquêmica do coração nas capitais de regiões metropolitanas do Brasil, 1979-89. Arq Bras Cardiol 1995; 64: 213-6.
4. Uemura K, Pisa Z. Trends in cardiovascular disease mortality in industrialized countries since 1950. World Health Statist Q 1988; 41: 155-78.

5. Centers for Disease Control. Trends in ischemic heart disease mortalaity. United States, 1980-1988. MMWR Morb Mortal Wkly Rep 1992; 41: 548-9.

6. Centers for Disease Control and Prevention. Trends in ischemic heart disease deaths. United States, 1990-1994. MMWR Morb Mortal Wkly Rep 1997; 46: 146-50.

7. Datasus. http://www.datasus.gov.br - Informação direta, 1999. 